\title{
Medication discrepancies in a hospital in Southern Brazil: the importance of medication reconciliation for patient safety
}

\author{
Alessandra de Sá Soares ${ }^{1,2}$, Daisson José Trevisol ${ }^{1,2}$, Fabiana Schuelter-Trevisol ${ }^{\circledR 1,2}$ \\ ${ }^{1}$ Universidade do Sul de Santa Catarina, Curso de Graduação em Farmácia e Bioquímica \\ da Universidade do Sul de Santa Catarina (Unisul), Tubarão, Santa Catarina, Brasi, \\ ${ }^{2}$ Universidade do Sul de Santa Catarina, Programa de Pós-Graduação em Ciências \\ da Saúde da Universidade do Sul de Santa Catarina (Unisul) e Centro de Pesquisas \\ Clínicas do Hospital Nossa Senhora da Conceição, Tubarão, Santa Catarina, Brasil
}

\begin{abstract}
Medication discrepancies are of great concern in hospitals because they pose risks to patients and increase health care costs. The aim of this study was to estimate the prevalence of inconsistent medication prescriptions to adult patients admitted to a hospital in southern Santa Catarina, Brazil. This was a patient safety study on patients recruited between November 2015 and June 2016. The participants were interviewed and had their medical records reviewed. Discrepant medications were considered those that did not match between the list of medicines taken at home and the prescribed drugs for treatment in a hospital setting. Of the 394 patients included, $98.5 \%$ took continuous-use medications at home, with an average of 5.5 medications per patient. Discrepancies totaled $80.2 \%$, The independent variables associated with the discrepancies were systemic arterial hypertension, hypercholesterolemia, vascular disease, number of medications taken at home, and poor documentation of the medications in the medical record. Findings from this study allowed us to conclude there was a high rate of prescription medication misuse. Medication reconciliation is crucial in reducing these errors. Pharmacists can help reduce these medication-related errors and the associated risks and complications.
\end{abstract}

Keywords: Patient Safety. Drug Use. Medication Reconciliation. Medication Errors

\section{INTRODUCTION}

Patient safety in health care is a basic requirement that reflects the quality of care provided within health institutions (WHO, 2003; Parand et al.,2014). Incidents are situations that may result in harm to patients during care provided by health care professionals, not associated with the patient's underlying disease (WHO, 2015; Pippins et al., 2008; van Melle et al., 2016). Health organizations designate an injury incident, also called an adverse event, as "impairment of body structure or function and impairments thereof, including physical, social or psychological dysfunction, illness,

*Correspondence: F. Schuelter-Trevisol. Universidade do Sul de Santa Catarina (Unisul). Avenida José Acácio Moreira, 787. Tubarão, Santa Catarina, CEP 88704-900, Brasil. Phone: (+55 048) 3631-7062. E-mail: fastrevisol@gmail.com injury, disability or suffering, and death" (WHO, 2003; Runciman et al., 2009; Leistikow et al., 2017; Tejal, Danald, Kaveh, 2016). Adverse drug reactions, medication errors, and drug discrepancies are among the drug-related incidents (WHO, 2009).

Medication reconciliation is a process designed to prevent discrepancies between home drug treatments and those conducted in hospital settings. Medication reconciliation can reduce errors and adverse events related to the prescription and use of medications. The purpose of this practice is to avoid or minimize transcription errors of medical prescription, omission of doses, and duplicity of therapy (Pippins et al., 2008).

Discrepancies are the incompatibilities found between the list of medicines taken at home and the prescription medicines in hospital settings used for disease treatment regarding the omission of 
doses, therapeutic duplicity, and non-prescription of medications for home use (Pippins et al., 2008; Sheikhtaheri, 2014). Discrepancies can be intentional or unintentional, of which the unintentional ones focused on patient safety programs (Runciman et al., 2009; Rodriguez et al., 2016). Previous studies have found that the patient's age, the number of medications prescribed, and the use of drugs for the cardiovascular system are likely to increase the number of discrepancies found. In addition, the small number of hospital pharmacists, lack of training and knowledge about the medication reconciliation service by pharmacists and other health team members also contribute to poor medication reconciliation (Huynh et al., 2016; Andreoli et al., 2014).

Prescription discrepancies have been studied for their effects (WHO, 2015; Pippins et al., 2008). Paying special attention to them in the pharmacotherapeutic treatments of hospitalized patients and improving health care quality and safety is beneficial not only to the patient, but also to the hospital and the health care system (Pippins et al., 2008).

Based on the foregoing background, the aim of this study was to estimate the prevalence of medication discrepancy between home medications for continuous use and those prescribed for the patient in the hospital. The study also aimed to evaluate the factors associated with these errors in a general hospital located in southern Santa Catarina, Brazil.

\section{METHOD}

This patient safety study was carried out in a 400bed hospital located in southern Santa Catarina, Brazil. Patients were surveyed in the medical clinic sector, which has 30 hospital beds and 100 monthly hospitalizations in average.

The study included adult patients of both genders and who had been hospitalized for at least 24 hours. The exclusion criteria encompassed subjects who had already been picked out earlier, those who were discharged at the time of the interview or were undergoing procedures and exams, and those who did not agree to participate or were unaccompanied at the time of the visit to respond to the survey questionnaire.

The population was composed of patients aged 18 years or over, whose hospitalization was covered by the National Unified Health System (SUS), from October 2015 to June 2016.
For sample calculation, an estimated population of 1,500 patients in the study period and a $60 \%$ incidence of discrepancies (WHO, 2009) were considered, with an increase of $20 \%$ for eventual losses or refusals, which resulted in a minimum sample size of 356 patients, for a $95 \%$ confidence interval. The patients were randomly selected by simple random sampling technique, using the patient's bed number.

The patients were interviewed just once, when information about medications taken at home or drugs prescribed in the hospital setting were collected. Afterwards, the patient's chart was consulted to compare the medical record prescription with the information provided by the patient during the interview. The medication reconciliation was performed for each patient by the researchers, using a data collection form.

The sociodemographic profile (age, gender, and education) were reported by the patient. Age was calculated by the difference between the date of the interview and the patient's date of birth, counted in full years; gender was identified as male or female, and full years of school attendance were taken into account to identify the education level. Clinical data, such reasons for hospitalization, length of hospital stay, if there was a transfer between hospital sectors, presence of comorbidities, prescribed medicines and the outcome - discharge or death, were extracted from the medical diagnosis noted in the electronic medical record. The cause of hospitalization was determined by the codes assigned according to the International Classification of Diseases. The length of hospital stay was calculated by the difference between the date of the patient's discharge or death and date of hospital admission, in days. The medications used at home and in the hospital were classified according to the Anatomical Therapeutic Chemical (ATC). The medical record of each patient was examined to identify which medications were used at home, how the info was obtained, and who had prescribed them.

In this study, polypharmacy was defined as the use of five or more medications simultaneously taken at home (Gnjidic et al., 2012).

After listing all medications taken at home and those prescribed during hospitalization, a comparison between them was made, classifying the drugs based on Page et al. (2010) and Andreoli et al. (2014) as follows: 1) continuous-use home medications neither prescribed in the hospital nor taken by or administered to the patient; 2) non-prescribed home medications, but taken 
by or administered to the patient; 3) home medications administered in duplicate (taken by the patient and administered by the nursing service in the hospital); 4) medication omission (medications prescribed, but not administered to the patient by the nursing service).

Medication discrepancy consisted of differences between the list of medicines taken at home and those prescribed for the treatment in a hospital setting, classified into one of the four categories listed above (Paci et al., 2015). The active principle of the medicine was considered to define discrepancy (no dosage or medication schedule was assessed). Medication discrepancy was categorized as follows; a) no discrepancy, when the full list of medicines used at home was included in the medical record; b) partial discrepancy, when the medical record did not contain one or more continuous-use medications informed by the patient; c) total discrepancy, when none of the medicines used at home were registered in the medical record.

The OpenEpi software, version 3.01, was used to calculate the sample size. The data collected were entered into Excel Workbook Gallery for Mac, 2011, version 14.6.6, and statistical analysis was performed using SPSS software v.21.0 (IBM Armonk, New York, USA).

The numerical variables were expressed as the mean or median and standard deviation (SD), and the nominal variables were presented as absolute and proportional values. The Kolmogorov-Smirnov test was used for quantitative variables to verify the normality of the data distribution. Student's t-test was used for mean comparison, and non-parametric statistics with Wilcoxon-Mann-Whitney U test was used for the nonnormal distribution of variables.

Prevalence ratios (PR) were calculated for independent variables, and discrepancies found in the medication prescriptions, crude analysis and, subsequently, adjusted for potential confounding variables, using modified Poisson regression models. Confounding factors were selected among variables associated with medication discrepancy, in the bivariate analysis (P-value $<0.20$ ), or those described as such in the literature (hospital stay and number home medications). A P-value $<0.05$ was considered statistically significant.

This study was approved by the Unisul Research Ethics Committee (Opinion No. 1.207.715), Plataforma Brasil (CAAE 47597615.0.0000.5369), on August 31, 2015. Study sample patients eligible for study were only included after signing an informed consent form.

\section{RESULTS}

During the study period, 448 patients were recruited, of whom 54 were excluded because of the following reasons: patients in isolation rooms, those unable to answer the questions, and those who were not in the room at the time of the interview, resulting in a final sample of 394 patients included in the study.

The participants' ages ranged from 18 to 97 years, with a mean of $61.6 \pm 15.1$ (median 62) years of age. The average length of hospital stay was 13.0 days (SD \pm 11.3 ), with a median of 10 days, ranging from 2 to 64 days. Circulatory system disorders were the leading cause of hospitalization, according to the International Code of Diseases (ICD10).

Table I presents a description of the sociodemographic and clinical characteristics of study participants admitted into the hospital and their association with drug discrepancies.

Of the 394 surveyed patients, 388 (98.5\%) took continuous-use medications at home, which corresponded to an average of 5.5 medications per patient (ranging from 1 to 18 medicines), whereas in the hospital setting, the average was 9.2 medications per patient (ranging from 1 to 31 medicines). By examining the list of medications taken at home to check whether they were prescribed during the hospital stay, we discovered that $956(43.8 \%)$ of the drugs were found to be in the medical prescription, 194 (8.9\%) drugs were replaced by drugs of the same class, and 1,031 (47.3\%) medicines were neither prescribed nor replaced, being considered omissions. Metformin was the most neglected drug (18.0\%) in the patients' prescriptions.

Drug discrepancy was associated with a higher number of medications consumed at home $(6.1 \pm 3.4)$ as compared to patients who did not present drug discrepancies $(3.7 \pm 2.8), \mathrm{p}<0.001$. Patients with prescriptions containing discrepancies totaled 316 $(80.2 \%)$. Of these, 72 presented prescriptions with more than one type of discrepancies, as illustrated in Figure 1.

The classes of medications most commonly used by patients at home and during the hospital stay are described in Table II. They were classified according to the anatomical group $\left(1^{\text {st }}\right.$ level $)$ of the ATC classification.

Adjusted analysis revealed that vascular disease, number of medication taken at home, and partial history of the medication in the medical record were independent factors associated to the occurrence of medication discrepancies, as shown in Table III. 
TABLE I - Analysis of the association between sociodemographic and clinical variables and medication discrepancies in the surveyed hospital, 2015-2016 $(\mathrm{n}=394)$

\begin{tabular}{|c|c|c|c|c|}
\hline Variable & Total n(\%) & Discrepancy n (\%) & PR (95\% CI) & P-value \\
\hline \multicolumn{5}{|l|}{ Gender } \\
\hline Male & $145(36.8)$ & $108(74.5)$ & 1.0 & \\
\hline Female & $249(63.2)$ & $208(83.5)$ & $1.07(1.00-1.15)$ & $0.030^{*}$ \\
\hline \multicolumn{5}{|c|}{ Age (years) } \\
\hline $18-59$ & $76(19.3)$ & $134(42.4)$ & 1.0 & \\
\hline$>59$ & $318(80.7)$ & $182(57.6)$ & $1.15(1.03-1.28)$ & $0.003^{*}$ \\
\hline \multicolumn{5}{|c|}{ School attendance (years) } \\
\hline $0-8$ & $335(85.0)$ & $270(85.4)$ & $0.97(0.89-1.07)$ & \\
\hline$>8$ & $59(15.0)$ & $46(14.6)$ & 1.0 & 0.640 \\
\hline \multicolumn{5}{|c|}{ Hospital stay (days) } \\
\hline $1-7$ & $142(36.0)$ & $111(35.1)$ & $1.03(0.95-1.12)$ & 0.513 \\
\hline $8-15$ & $149(37.9)$ & $121(38.3)$ & $1.00(0.92-1.09)$ & 0.945 \\
\hline$>15$ & $103(26.1)$ & $84(26.6)$ & 1.0 & \\
\hline
\end{tabular}

Associated comorbidities

\begin{tabular}{lcccc} 
Neoplasia & $18(4.6)$ & $13(72.2)$ & $1.07(0.90-1.26)$ & 0.273 \\
DM & $129(32.7)$ & $109(84.5)$ & $0.94(0.88-1.01)$ & 0.136 \\
Hypercholesterolemia & $95(24.1)$ & $86(90.5)$ & $0.88(0.83-0.95)$ & $0.004^{*}$ \\
SHA & $271(68.8)$ & $232(85.6)$ & $0.86(0.80-0.93)$ & $<0.01^{*}$ \\
Psychiatric illness & $64(16.2)$ & $57(89.1)$ & $0.91(0.84-0.98)$ & 0.052 \\
Pulmonary disease & $52(13.2)$ & $41(78.8)$ & $1.01(0.91-1.11)$ & 0.792 \\
Vascular disease & $69(17.5)$ & $50(72.5)$ & $1.08(0.98-1.18)$ & 0.076 \\
\hline Sector transfer & & & \\
Yes & $128(32.5)$ & $105(82.0)$ & $0.97(0.91-1.04)$ & 0.528 \\
No & $266(67.5)$ & $211(79.3)$ & 1.0 & \\
\hline
\end{tabular}

Number of medicines taken at home

$1-4$
$5-9$

$168(43.0)$

$167(42.7)$

$56(14.3)$

$118(70.2)$
$146(87.4)$
$52(92.9)$

1.0

$>9$

$33(8.4)$

$191(48.5)$

$170(43.1)$

umber of medicines prescribed at hospital

$$
\begin{aligned}
& 1-4 \\
& 5-9 \\
& >9
\end{aligned}
$$

History of home medicine

in the medical chart

\begin{tabular}{lcccc} 
Yes & $68(17.3)$ & $50(73.5)$ & 1.0 & \\
No & $292(74.1)$ & $235(80.5)$ & $0.95(0.86-1.04)$ & 0.225 \\
Partial & $34(8.6)$ & $31(91.2)$ & $0.86(0.76-0.97)$ & $0.015^{*}$ \\
\hline
\end{tabular}


TABLE I - Analysis of the association between sociodemographic and clinical variables and medication discrepancies in the surveyed hospital, 2015-2016 ( $\mathrm{n}=394)$

\begin{tabular}{lcccc}
\hline Variable & Total n(\%) & Discrepancy n (\%) & PR (95\% CI) & P-value \\
\hline $\begin{array}{l}\text { Prescriber } \\
\text { Physician }\end{array}$ & $207(52.5)$ & $166(80.2)$ & $1.00(0.93-1.06)$ & 0.996 \\
Resident & $187(47.5)$ & $150(80.2)$ & 1.0 & 0.422 \\
\hline $\begin{array}{l}\text { Death } \\
\text { Yes }\end{array}$ & $40(10.2)$ & $34(85.0)$ & $0.95(0.86-1.05)$ & 1.0 \\
No & $354(89.8)$ & $282(79.7)$ & & 0.056 \\
\hline $\begin{array}{l}\text { Home Medication Information Source } \\
\text { Medical prescription }\end{array}$ & $14(3.5)$ & $12(85.7)$ & $0.92(0.78-1.09)$ & \\
$\quad \begin{array}{l}\text { Patient notes } \\
\text { Memory }\end{array}$ & $117(29.7)$ & $102(87.2)$ & $0.91(0.85-0.98)$ & \\
\hline
\end{tabular}

${ }^{*} \mathrm{p}<0.05 ; \S$ Some patients had more than one comorbidity

$\mathrm{PR}=$ prevalence ratio; $\mathrm{DM}=$ diabetes mellitus; $\mathrm{SAH}=$ systemic arterial hypertension.

TABLE II - Most frequently prescribed drugs of the classes used in the home and hospital prescriptions by study participants hospitalized in the period from 2015 to 2016

\begin{tabular}{|c|c|c|c|c|c|c|c|c|c|c|c|}
\hline \multirow{3}{*}{ Code } & \multirow{3}{*}{ Contents } & \multirow{2}{*}{\multicolumn{2}{|c|}{ Home }} & \multicolumn{8}{|c|}{ Prescription frequency } \\
\hline & & & & \multicolumn{3}{|c|}{ Main medications } & \multicolumn{2}{|c|}{ Hospital } & \multicolumn{3}{|c|}{ Main medications } \\
\hline & & $\mathbf{n}$ & $\%$ & & $\mathbf{n}$ & $\%$ & $\mathbf{n}$ & $\%$ & & $\mathbf{n}$ & $\%$ \\
\hline A & $\begin{array}{l}\text { Alimentary tract } \\
\text { and metabolism }\end{array}$ & 363 & 16.7 & Omeprazole & 100 & 27.5 & 712 & 19.6 & Omeprazole & 217 & 30.5 \\
\hline B & $\begin{array}{l}\text { Blood and blood } \\
\text { forming organs }\end{array}$ & 227 & 10.4 & Acetylsalicylic acid & 127 & 55.9 & 613 & 16.9 & Enoxaparin & 165 & 26.9 \\
\hline $\mathrm{C}$ & Cardiovascular system & 808 & 37.3 & Losartan & 137 & 17.0 & 772 & 21.3 & Losartan & 102 & 13.2 \\
\hline $\mathrm{D}$ & Dermatological & 9 & 0.4 & Collagenase & 2 & 22.2 & 45 & 1.2 & Collagenase & 30 & 66.7 \\
\hline G & $\begin{array}{l}\text { Genitourinary system } \\
\text { and sex hormones }\end{array}$ & 15 & 0.7 & Isoflavone & 3 & 20.0 & 0 & 0 & - & - & - \\
\hline $\mathrm{H}$ & $\begin{array}{l}\text { Systemic hormonal } \\
\text { preparations, excluding } \\
\text { sex hormones and insulins }\end{array}$ & 62 & 2.8 & Levothyroxine & 44 & 71.0 & 78 & 2.2 & Methylprednisolone & 34 & 43.6 \\
\hline
\end{tabular}


TABLE II - Most frequently prescribed drugs of the classes used in the home and hospital prescriptions by study participants hospitalized in the period from 2015 to 2016

\begin{tabular}{|c|c|c|c|c|c|c|c|c|c|c|c|}
\hline \multirow{3}{*}{ Code } & \multirow{3}{*}{ Contents } & \multirow{2}{*}{\multicolumn{2}{|c|}{ Home }} & \multicolumn{8}{|c|}{ Prescription frequency } \\
\hline & & & & \multicolumn{3}{|c|}{ Main medications } & \multicolumn{2}{|c|}{ Hospital } & \multicolumn{3}{|c|}{ Main medications } \\
\hline & & $\mathbf{n}$ & $\%$ & & $\mathbf{n}$ & $\%$ & $\mathbf{n}$ & $\%$ & & $\mathbf{n}$ & $\%$ \\
\hline $\mathrm{J}$ & $\begin{array}{l}\text { Anti-infective for } \\
\text { systemic use }\end{array}$ & 19 & 0.9 & $\begin{array}{c}\text { Ethambutol } \\
+ \text { isoniazid }+ \\
\text { pyrazinamide }\end{array}$ & 2 & 10.5 & 267 & 7.5 & Ceftriaxone & 79 & 29.6 \\
\hline $\mathrm{L}$ & $\begin{array}{c}\text { Antineoplastic and } \\
\text { immunomodulating } \\
\text { agents }\end{array}$ & 13 & 0.6 & Methotrexate & 5 & 38.5 & 0 & 0 & - & - & - \\
\hline M & Musculoskeletal system & 70 & 3.2 & $\begin{array}{l}\text { Diclofenac }+ \\
\text { associations }\end{array}$ & 13 & 18.6 & 102 & 2.8 & Ketoprofen & 73 & 71.6 \\
\hline $\mathrm{N}$ & Nervous system & 466 & 21.5 & Clonazepam & 73 & 18.5 & 787 & 21.7 & Dipyrone & 258 & 32.8 \\
\hline $\mathrm{P}$ & $\begin{array}{l}\text { Antiparasitic products, } \\
\text { insecticides and repellents }\end{array}$ & 7 & 0.3 & Dimeticone & 3 & 42.9 & 10 & 0.3 & Albendazole & 5 & 50.0 \\
\hline $\mathrm{R}$ & Respiratory system & 110 & 5.0 & $\begin{array}{c}\text { Budesonide }+ \\
\text { Formoterol }\end{array}$ & 28 & 25.5 & 232 & 6.3 & Diphenhydramine & 58 & 25.0 \\
\hline $\mathrm{S}$ & Sensory organs & 5 & 0.2 & $\begin{array}{l}\text { Hypromellose } \\
\text { + Dextran }\end{array}$ & 4 & 80.0 & 7 & 0.2 & $\begin{array}{c}\text { Retinol + } \\
\text { combinations }\end{array}$ & 4 & 57.1 \\
\hline Total & & $2,1^{7}$ & & & & & 3,6 & & & & \\
\hline
\end{tabular}

TABLE III - Crude and adjusted analysis of the independent variables related to the occurrence of drug discrepancy among the study participants hospitalized in the surveyed hospital, 2015-2016

\begin{tabular}{|c|c|c|c|c|c|}
\hline \multirow[b]{2}{*}{ Variable } & \multirow[b]{2}{*}{ n (\%) } & \multicolumn{4}{|c|}{ PR (95\% CI) } \\
\hline & & Crude analysis & P-value & $\begin{array}{l}\text { Adjusted } \\
\text { analysis }\end{array}$ & P-value \\
\hline Women & $249(63.2)$ & $1.05(1.00-1.10)$ & 0.038 & $0.97(0.93-1.02)$ & 0.273 \\
\hline Age $>59$ years & $230(58.4)$ & $1.15(1.02-1.11)$ & 0.009 & $1.03(0.99-1.08)$ & 0.179 \\
\hline DM & $129(32.7)$ & $1.04(0.99-1.08)$ & 0.116 & $1.00(0.95-1.05)$ & 0.994 \\
\hline Hypercholesterolemia & $95(24.1)$ & $1.08(1.03-1.12)$ & $<0.001$ & $1.03(0.98-1.08)$ & 0.202 \\
\hline
\end{tabular}


TABLE III - Crude and adjusted analysis of the independent variables related to the occurrence of drug discrepancy among the study participants hospitalized in the surveyed hospital, 2015-2016

\begin{tabular}{|c|c|c|c|c|c|}
\hline \multirow[b]{2}{*}{ Variable } & \multirow[b]{2}{*}{ n (\%) } & \multicolumn{4}{|c|}{ PR $(95 \%$ CI $)$} \\
\hline & & Crude analysis & P-value & $\begin{array}{l}\text { Adjusted } \\
\text { analysis }\end{array}$ & P-value \\
\hline $\mathrm{SAH}$ & $271(68.8)$ & $1.10(1.05-1.16)$ & $<0.001$ & $1.04(0.98-1.09)$ & 0.206 \\
\hline Psychiatric disease & $64(16.2)$ & $1.06(1.01-1.11)$ & 0.017 & $1.03(0.98-1.08)$ & 0.227 \\
\hline Vascular disease & $69(17.5)$ & $0.95(0.88-1.01)$ & 0.112 & $0.93(0.87-0.99)$ & $0.019^{*}$ \\
\hline $\begin{array}{l}\text { Partial history of home medications } \\
\text { in the medical record }\end{array}$ & $34(8.6)$ & $1.10(1.02-1.19)$ & 0.015 & $1.11(1.03-1.19)$ & $0.004 *$ \\
\hline Patient's notes & $117(29.7)$ & $1.06(1.01-1.11)$ & 0.010 & $0.98(0.88-1.08)$ & 0.627 \\
\hline Time of hospitalization in days (median) & 10 & $1.00(0.99-1.01)$ & 0.904 & $1.00(0.99-1.01)$ & 0.998 \\
\hline Number of medications at home (median) & 5 & $1.02(1.01-1.02)$ & $<0.001$ & $1.01(1.01-1.02)$ & $<0.001^{*}$ \\
\hline
\end{tabular}

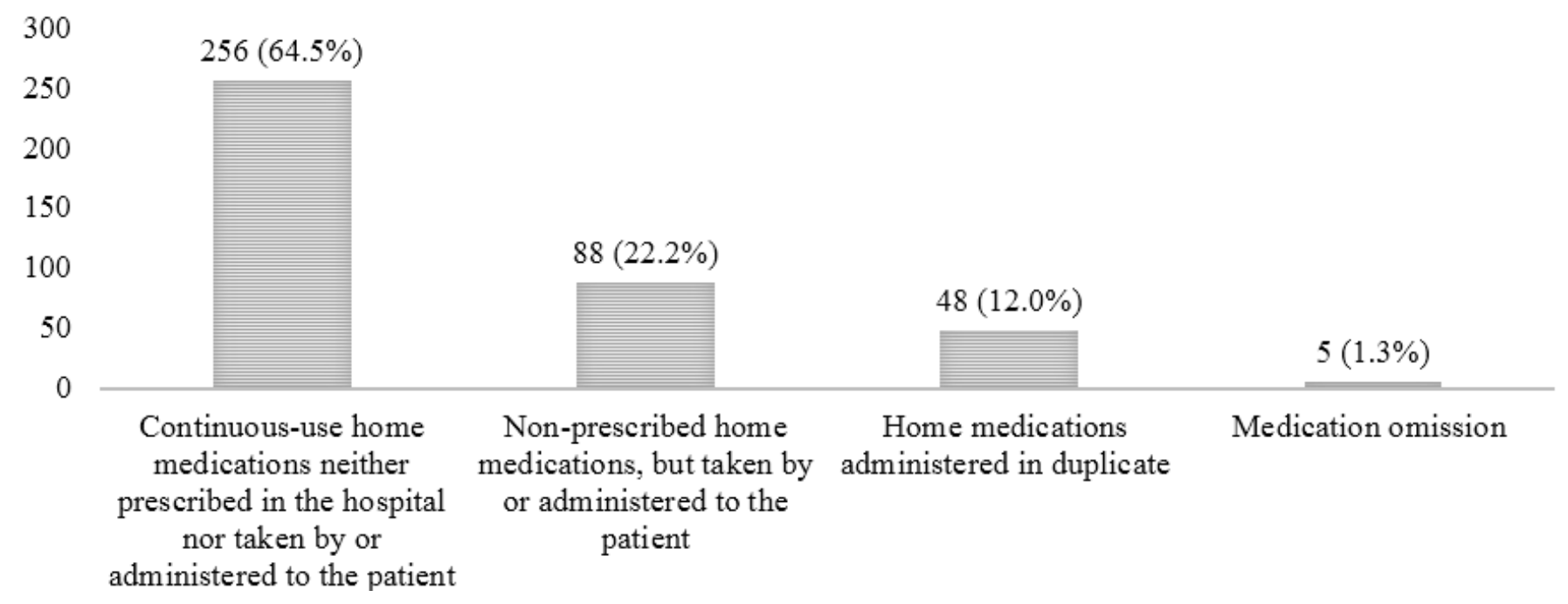

Some prescriptions presented more than one discrepancy.

FIGURE I - Distribution of types of drug discrepancy found among the study participants during their hospital stay, 2015-2016. 


\section{DISCUSSION}

This study focused primarily on the assessment of drug discrepancies in the prescriptions for hospitalized patients. There was a high frequency $(80.2 \%)$ of drug discrepancies in comparison to other studies (Zoni et al., 2012; Bishop et al., 2015), which ranged from 19.1\% to $51 \%$. More recently, a study conducted by Armor et al. (2014) found a frequency of $81 \%$ of drug discrepancies. It should be noted that in the surveyed hospital there was neither a drug reconciliation service, nor the presence of clinical pharmacists. The percent variability may depend on the characteristics of the hospital health care and the way the data collection of medicines taken at home is made.

In this study, household polypharmacy was considered a factor associated with the presence of medication discrepancy or error. It can be attributed to the higher mean age of the study participants as compared to other age groups. In the present study, the number of drugs used at home and in the hospital can be classified as polypharmacy, since the average number of drugs was 5.5 and 9.2 per patient, respectively. Polypharmacy may lead to the appearance of iatrogenic diseases, which are responsible for increased morbidity and mortality, large number of hospitalizations, and high costs to health care systems (Armor et al., 2014; Ferreira, Rodrigues, 2012). Patients using various medications are usually more vulnerable to medication errors, with a large proportion of elderly people presenting more than one comorbidity and/or chronic diseases (Paci et al., 2015). This association may occur due to the pathophysiological process of aging, leading to greater intake of medications, iatrogenic cascade, and polypharmacy (Zoni et al., 2012).

The patient's adherence and understanding about the pharmacological treatment should also be considered a challenge in the reconciliation process, in which patients or family members have difficulty naming the medications used. In Brazil, this is even more aggravating because we do not have a computerized dispensing system or adequate communication between commercial establishments (pharmacies), public health services, and hospitals. The same occurs with communications between different health professionals (prescribers and pharmacists) (Ferreira, Rodrigues 2012; Coutinho et al., 1999).

Diseases of the circulatory system were the most prevalent illnesses among the hospitalized patients, a situation that can be attributed to the fact that most participants were of an advanced age (Saint-German et al., 2016). Hypertension, hypercholesterolemia, and $\mathrm{DM}$ are the major factors for the onset of cardiovascular diseases and polypharmacy, requiring a great amount of medication to treat these disorders, which may increase the rate of hospital admissions due to these causes (Afaras et al., 2016; Charlesworth et al., 2015). In the general population, hypertension and DM prevalence rates were $21.4 \%$ and $6.2 \%$, respectively. (Pesquisa Nacional de Saúde, 2013).

The adjusted analysis revealed that vascular diseases was independent factor associated with the occurrence of drug discrepancies. Andreoli et al. (2014) have corroborated this finding, since their study showed that the age of the patient, the number of medications prescribed, and the use of drugs for the cardiovascular system may increase the number of discrepancies.

Drug reconciliation has different forms to classify discrepancies by using varied instruments, according to the clinical pharmacist's needs. Medical prescriptions of home medicines, medication packages, and lists prepared by the patients or their caregivers can be used to collect the data. In this study, the majority of the participants (76.8\%) did not take to the hospital any documentation describing their continuous-use medications, so memory was then the most common source of information. Memory was also the most common (94.1\%) resource used by an emergency service in a study by Cater et al. (2015). Coutinho et al. (1999) have argued that one can rely on information provided by the patient regarding medications used within two weeks prior to interview, and whenever the patient's cognitive functions do not allow it, that information can be obtained from their caregivers (Cater et al., 2015), but in both cases the information must be confirmed by the pharmacist as soon as possible. The prescriber's lack of confidence in patients' oral information regarding medication use may also be one of the causes of discrepancies.

Assessment of home medications revealed that a high percentage of medicines taken at home were considered neglected, and a few were replaced by drugs of the same class. This replacement may have occurred because of the standardization of medications adopted by the hospital, which led physicians to prescribe active principles available at the hospital pharmacy. Differences between medications taken at home and those prescribed in the hospital that caused no changes in the patient's clinical condition may be considered 
discrepancies. It should be noted that all neglected drugs were standardized in the surveyed hospital. In a study conducted by Cater et al. (2015), the percentage of prescribed medicines taken at home (33.9\%) was very close to that found in the present study.

In this study, the five most commonly neglected drugs were metformin, followed by losartan, acetylsalicylic acid, hydrochlorothiazide, and levothyroxine, all of which are used to treat chronic diseases. It was impossible to identify whether the medication discrepancies were intentional, even though interrupting a disease treatment abruptly should be very rare, especially without a documented reasoning. There is no evidence if an abruptly withdrawal of metformin, levothyroxine, and losartan may cause rebound effect after sudden discontinuation. However, omissions of these medications may lead to hyperglycemia, hypothyroidism, and augmented blood pressure levels, respectively, posing risks to patients' health. A sudden withdrawal of acetylsalicylic acid may be associated with traditional cardiovascular risk factors and thrombosis. A sudden withdrawal of hydrochlorothiazide from patients with normal sodium intake may cause rebound retention of sodium and water, leading to edema through compensatory mechanism (Medication Reconciliation, 2009; Kalb et al., 2009).

Different studies (Comino et al., 2015, Oliveira Filho et al., 2014; Beckett, Crank, Wehmeyer, 2012; Hellström et al., 2012) have classified medication discrepancies, and the most frequent discrepancies was non-prescription drugs taken at home, which corroborates the findings of this study. Discrepancies in nonprescription medications taken by the patients or administered to them by their caregivers encountered additional problems, such as forgetfulness, inadequate drug storage and poor administration, lack of knowledge of the practice by the health team, and consequently, poor assessment of the interactions with the medications prescribed in the hospital.

Therapeutic duplicity occurred in $12 \%$ of the prescriptions, i.e., 48 patients reported they were taking their home medicines, which were the same (or same class) being prescribed and administered in the hospital. Therapeutic duplicity may increase the risk of adverse reactions and interactions. Especially the benzodiazepine-related duplicity can lead to excessive sedation, risk of falls and fractures, mental confusion, and benzodiazepine poisoning symptoms (Johnson, Streltzer, 2013).
The use of medicines can be complex and vulnerable to iatrogenic diseases, especially in hospitals where a large team is involved in the patient treatment. Medication use encompasses important steps, such as prescription, communication, dispensing, administration, and clinical follow-up (Johnson, Streltzer, 2013; Doerper et al., 2015). The lack or poor communication, whether written or oral, can lead to all errors occurring within hospitals, therefore, the lack of the documented drug history may result in potentially harmful discrepancies, leading to imprecise and sometimes fatal treatment (Beckett, Crank, Wehmeyer, 2012).

Data presented here should be viewed with relative caution, due to the short time available to classify the discrepancies found. There are also some limitations related to the intentionality and epidemiological design of the study. Further longitudinal studies should be carried out to evaluate clinical implications of drug discrepancies. Impact studies of the drug reconciliation service are also needed to strengthen the implementation of this practice in hospital settings.

Despite these limitations, the study presents an important outcome that may have negative impacts on the patient, the health team, and the institution. The reconciliation may also be applied at discharge from hospital, for continuity of treatment, and may provide guidance on discharge prescriptions that may contain manipulated medications, lack of important information, duration of treatment, use of abbreviations or illegible prescriptions (van Melle et al., 2016). Further studies on medication reconciliation at hospital discharge should be conducted.

\section{CONCLUSION}

Findings from this study allowed us to conclude there was a high rate of patients with prescription medication misuse ( $80.2 \%$ discrepancies). Assessment of medication use revealed that vascular disease, number of continuous-use medications at home, and poor documentation in the medical record were independent factors associated with medication discrepancies. Medication reconciliation is crucial in reducing these errors. Pharmacists can help reduce these medication-related errors and the associated risks and complications. 


\section{REFERENCES}

Alfaras I, Di Germanio C, Bernier M, Csiszar A, Ungvari Z, Lakatta EG, et al. Pharmacological strategies to retard cardiovascular aging. Circ Res. 2016;118(10):1626-42.

Andreoli L, Alexandra JF, Tesmoingt C, Eerdekens C, Macrez A, Papo T, et al. Medication reconciliation: a prospective study in an internal medicine unit. Drugs Aging. 2014;31(5):387-9.

Armor BL, Wight AJ, Carter SM. Evaluation of adverse drug events and medication discrepancies in transitions of care between hospital discharge and primary care follow-up. J Pharm Pract. 2014;29(2):132-7.

Beckett RD, Crank CW, Wehmeyer A. Effectiveness and feasibility of pharmacist-led admission medication reconciliation for geriatric patients. J Pharm Pract. 2012;25(2):136-41.

Bishop MA, Cohen BA, Fashp MS, Billings LK, Thomas EV. Reducing errors through discharge medication reconciliation by pharmacy services. Am J Health Syst Pharm. 2015;72(17 Suppl 2):S120-6.

Cater SW, Luzum M, Serra AE, Arasaratnam MH, Travers D, Martin IBK, et al. A prospective cohort study of medication reconciliation using pharmacy technicians in the emergency department to reduce medication errors among admitted patients. J Emergency Med. 2015;48(2):230-8.

Charlesworth CJ, Smit E, Lee DSH, Alramadhan F, Odden MC. Polypharmacy among adults aged 65 years and older in the United States: 1988-2010. J Gerontolog A Biol Sci Med Sci. 2015;70(8):989-95. doi:10.1093/gerona/glv013.

Comino EJ, Harris MF, Islam MF, Tran DT, Jalaludin B, Jorm $\mathrm{L}$, et al. Impact of diabetes on hospital admission and length of stay among a general population aged 45 year or more: a record linkage study. BMC Health Serv Res. 2015;15:12.

Coutinho ESF, Silva SD, Paiva CHA, Freitas GG, Miranda LP, Mendonça R. Confiabilidade da informação sobre uso recente de medicamentos em um estudo caso-controle de base hospitalar. Cad Saúde Pública. 1999;15(3):553-8.

Doerper S, Godet J, Alexandra JF, Allenet B, Andres E, Bedouch P, et al. Development and multi-centre evaluation of a method for assessing the severity of potential harm of medication reconciliation errors at hospital admission in elderly. Eur J Intern Med. 2015;26(7):491-7.

Ferreira NML, Rodrigues VMCP. Assessment of the impact of polypharmacy on funding for admission in a long-term care and maintenance unit. Rev Enf Ref. 2012;(6):17-24.
Gnjidic D, Hilmer SN, Blyth FM, Naganathan V, Waite L, Seibel MJ, et al. Polypharmacy cutoff and outcomes: five or more medicines were used to identify community-dwelling older men at risk of different adverse outcomes. J Clin Epidemiol. 2012;65(9):989-95.

Hellström LM, Bondesson A, Hoglund P, Eriksson T. Errors in medication history at hospital admission: prevalence and predicting factors. BMC Clin Pharmacol 2012;12:9.

Huynh C, Tomlin S, Jani Y, Solanki GA, Haley H, Smith $\mathrm{RE}$, et al. An evaluation of the epidemiology of medication discrepancies and clinical significance of medicines reconciliation in children admitted to hospital. Arc Dis Child. 2016;101(1):67-71.

Johnson B, Streltzer J. Risks associated with long-term benzodiazepine use. Am Fam Physician. 2013;88(4):224-5.

Kalb K, Shalansky S, Legal M, Khan N, Ma I, Hunte G. Unintended medication discrepancies associated with reliance on prescription databases for medication reconciliation on admission to a general medical ward. Can J Hosp Pharm. 2009;62(4):284-9.

Leistikow I, Mulder S, Vesseur J, Robben P. Learning from incidents in healthcare: the journey, not the arrival, matters. BMJ Qual Saf. 2017 Mar;26(3):252-6.

Medication Reconciliation: A Learning Guide. 2009. https://meds.queensu.ca/central/assets/modules $/ \mathrm{mr} / 1 . \mathrm{html}$. Accessed 30 Set 2017.

Oliveira-Filho AD, Morisky DE, Costa FA, Pacheco Sara T, Neves SF, Lyra-Jr DP. Improving Post-Discharge Medication Adherence in Patients with CVD: A Pilot Randomized Trial. Arq Bras Cardiol. 2014;103(6):503-12.

Paci JF, Alfaro MG, Alonso FJR, San-Martín MIF. Prescripción inadecuada en pacientes polimedicados mayores de 64 años en atención primaria. Aten Primaria. 2015;47(1):38-47.

Page RL, Linnebur SA, Bryant LL, Ruscin JM. Inappropriate prescribing in the hospitalized elderly patient: Defining the problem, evaluation tools, and possible solutions. Clin Interv Aging. 2010;5:75-87.

Parand A, Dopson S, Renz A, Vincent C. The role of hospital managers in quality and patient safety: a systematic review. BMJ Open. 2014;4(9):e005055. https://doi.org/10.1136/ bmjopen-2014-005055.

Pesquisa Nacional de Saúde 2013: percepção do estado de saúde, estilos de vida e doenças crônica - Brasil, Grandes Regiões e Unidades da Federação. Rio de Janeiro: Instituto Brasileiro de Geografia e Estatística, 2014. 
Pippins JR, Gandhi TK, Hamann C, Ndumele CD, Labonville $\mathrm{SA}$, Carty $\mathrm{MG}$, et al. Classifying and predicting errors of inpatient medication reconciliation. J Gen Intern Med. 2008;23(9):1414-22.

Rodriguez VB, Delgado SE, Peinado I, Bermejo VT. Prevalence and risk factors for medication reconciliation errors during hospital admission in elderly patients. Int J Clin Pharm. 2016;38(5):1164-71.

Runciman W, Hibbert P, Thomson R, Schaaf TV, Sherman H, Lewalle P. Towards an International Classification for Patient Safety: key concepts and terms. Int J Qual Health Care. 2009;21(1):18-26.

Saint-German P, Ruelle M, Mary A, Sid Idris S, Hannat $\mathrm{S}$, Pelloquin $\mathrm{N}$, et al. The clinical impact of treatment discrepancies recorded for 200 patients in an acute geriatric unit. Rev Med Interne 2016;37(10):667-73.

Sheikhtaheri A. Near misses and their importance for improving patient safety. Iran J Public Health. 2014;43(6):853-54.

Tejal KG, Donald MB, Kaveh GS. Patient Safety at the Crossroads. JAMA. 2016;315(17):1829-30. van Melle MA, Erkelens DCA, van Stel HF, de Wit NJ, Zward DL. Pilot study on identification of incidents in healthcare transitions and concordance between medical records and patient interview data. BMJ Open 2016;6(8):e011368.

World Health Organization. Fifty-fifth World Health Assembly. A55/13. Quality of care: patient safety. 2003. http://www.who.int/patientsafety/worldalliance/ea5513.pdf. Accessed 20 Nov 2017.

World Health Organization. World Alliance for Patient Safety, Taxonomy: The Conceptual Framework for the International Classification for Patient Safety. 2009. http://www.who.int/ patientsafety/taxonomy/icps_full_report.pdf. Accessed 31 Jul 2017

World Health Organization. World Alliance for Patient Safety. 2015. Geneva. http://www.who.int/patientsafety/ worldalliance/en/. Accessed 31 Oct 2017.

Zoni AC, Durán García MED, Jiménez Muñoz AB, Salomón Pérez R, Martin P, Herranz Alonso A. The impact of medication reconciliation program at admission in an internal medicine department. Eur J Intern Med 2012;23(8):696-700.

Received for publication on $10^{\text {th }}$ December 2018 Accepted for publication on $15^{\text {th }}$ September 2019 